\title{
In vitro and in vivo bactericidal activity of Tinospora sagittata (Oliv.) Gagnep. var. craveniana (S.Y.Hu) Lo and its main effective component, palmatine, against porcine Helicobacter pylori
}

\author{
Qian Rong, Min Xu, Qi Dong, Yuli Zhang, Yinglun Li*, Gang Ye and Ling Zhao
}

\begin{abstract}
Background: Tinospora sagittata (Oliv.) Gagnep. var. craveniana (S.Y.Hu) Lo (TSG) is a traditional Chinese herb that has been used for the treatment of upper respiratory tract infection and has anti-bacterial and anti-ulcer activity. Our study investigated the bactericidal effects of TSG and its major component, palmatine, against a Helicobacter pylori (H. pylori) strain isolated from pig and the standard strain H. pylori SS1 in vitro and in vivo.

Methods: H. pylori was isolated from pig and named H. pylori SCYA201401. For in vitro experiments, the inhibitory activity of TSG and palmatine against H. pylori SCYA201401 and H. pylori SS1 were tested by use of the agar cup diffusion technique. The minimal inhibitory concentration (MIC) and minimal bactericidal concentration (MBC) were determined from the absence of $\mathrm{H}$. pylori colonies on agar plates. Time-kill curves were used to evaluate bactericidal activity; the average number of colonies was calculated at 0 to $48 \mathrm{~h}$ after liquid incubation, with concentrations of drugs at 0.5, 1, and $2 \times$ MIC. For in vivo experiments, H. pylori SCYA201401-infected mice were randomly divided into TSG, palmatine, triple therapy (omeprazole, clarithromycin, and amoxicillin), blank control, and model groups. The eradication ratios were determined by use of rapid urease tests and bacterial culture.

Results: In vitro, the MIC and MBC of TSG against H. pylori SCYA201401 and SS1 were both $6250 \mu \mathrm{g} / \mathrm{mL}$, whereas palmatine against H. pylori SCYA201401 was $6.25 \mu \mathrm{g} / \mathrm{mL}$ and against H. pylori SS1 was $3.12 \mu \mathrm{g} / \mathrm{mL}$. The time-kill curves showed a dose-dependent, progressive decline in the numbers of viable bacteria up to $40 \mathrm{~h}$. In vivo, the eradication ratios in the TSG and palmatine groups of mice were 80 and $50 \%$ compared with $70 \%$ in the triple-therapy group.
\end{abstract}

Conclusion: TSG and its major component, palmatine, have bactericidal activity against $H$. pylori in vitro and in vivo. The possibility that TSG or palmatine can be effective in the treatment of human and animals $\mathrm{H}$. pylori infection deserves investigation.

Keywords: Helicobacter pylori, Bactericidal activity, Tinospora sagittata (Oliv.) Gagnep. var. craveniana (S.Y.Hu) Lo, Palmatine

Abbreviations: dNTPs, Deoxynucleotide triphosphates; H. pylori, Helicobacter pylori; MIC, Minimal inhibitory concentration; RUT, Rapid urease test; SS1, Sydney strain 1; TSG, Tinospora sagittata (Oliv.) Gagnep. var. craveniana (S.Y.HU) LO

* Correspondence: liyinglun01@163.com

College of Veterinary Medicine, Sichuan Agricultural University, Chengdu,

Sichuan 611130, People's Republic of China 


\section{Background}

Helicobacter pylori (H. pylori) is a gram-negative bacterium, usually in a spiral-shaped form, which can be converted into coccoid cells under a hostile environment. $H$. pylori infection often is associated with gastrointestinal diseases, such as chronic gastritis, peptic ulcer, gastric carcinoma, and mucosa-associated lymphoid tissue lymphoma [1-7].

$H$. pylori colonizes the stomach of more than half of the world's human population, but its mode of transmission remains unknown. Some reports indicate there is a higher prevalence of antibodies against this bacterium in veterinarians, butchers, and slaughterers than in other people, which suggests the possibility of zoonotic transmission [8-10]. Recently, investigators have isolated $H$. pylori from cows, sheep, camels, miniature pigs, and dogs' milk. The isolated method for each animal is slightly different $[11,12]$.

Current treatment and eradication of $H$. pylori involve the use of triple therapy consisting of two antibiotics, inhibition of gastric acid secretion by histamine $\mathrm{H}_{2}$-antagonists or proton pump inhibitors, and mucosal protection provided by sucralfate and bismuth. However, the organism's increasing antibiotic resistance and side effects arising from these drugs are creating a general health problem, indeed a global pandemic, which is especially severe in developing countries such as China [13]. Thus, safe and effective non-antibiotic agents are urgently needed. Accordingly, there is rekindled interest in the use of natural drugs, including herbs, which may possess anti-H. pylori activities [32] and also may have minimal side effects, easy accessibility, and affordability, even by the poor.

Traditional Chinese medicine has been used in Chinese health care for more than two thousand years. Side effects and adverse events of the traditional medicines are generally regarded as mild and infrequent [14-16]. Tinospora sagittata (Oliv.) Gagnep. var. craveniana (S.Y.Hu) Lo (TSG) is an important species of the genus Tinospora (Menispermaceae), a traditional Chinese Miao-nationality herb which only grows on the Mount Emei of Sichuan province, and has been widely used in the treatment of gastrointestinal diseases. TSG is listed in the Pharmacopeia of the People's Republic of China as a plant of origin for Tinospora sagittata (Oliv.) Gagnep, with anti-inflammatory, analgesic, anti-bacterial, anti-ulcer, anti-tumor, and antistress activities [17-20]. The main chemical constituents of Radix Tinosporae are diterpenoid lactone, protoberberine alkaloids, aporphine alkaloids, and botanic steroids, among which diterpenoid lactones and alkaloids are considered important bioactive constituents. Palmatine is one of the major alkaloid compounds in TSG.

This study isolated a clinical $H$. pylori strain from swine by an improved method and investigated the bactericidal activities of TSG and its major component, palmatine, against the clinical $H$. pylori strain and $H$. pylori SS1 in vivo and in vitro.

\section{Methods \\ Plant collection and extraction}

TSG plants were collected from Mount Emei (Sichuan, China) between the months of September and October, 2014. The plants were identified and authenticated by Professor Qiao-jia Fan of the College of Veterinary Medicine, Sichuan Agricultural University, Chengdu, China. A voucher specimen (TSG2014) was deposited in the Veterinary Medicine Department of Sichuan Agricultural University. We prepared an extract of TSG from the plants according to reported methods [21]. Air-dried TSG (500 g) was refluxed with $95 \%$ ethanol $(v / v)$ three times each for $2 \mathrm{~h}$. The solvent was completely removed in vacuo to generate a semisolid residue, which yielded $14.72 \%(w / w)$ dry starting material. Stock solutions of the freeze-dried extracts were prepared for the initial screening by reconstitution in $1 \%$ dimethyl sulfoxide (Amresco, America) to a final concentration of $1 \mathrm{~g} / \mathrm{mL}$.

\section{Chemicals and reagents}

Palmatine, amoxicillin, omeprazole, clarithromycin, and vancomycin were purchased from Shanghai Yuanye Biotechnology, Co., Ltd (Shanghai, China). Brucella broth, Columbia blood agar, and Mueller-Hinton agar were purchased from OXOID (Hampshire, UK).

\section{Bacterial strain}

H. pylori SS1 were purchased from the Chinese Center for Disease Control, Beijing.

\section{Sampling}

One hundred seventy gastric samples were randomly selected from pigs sent to the Xingrui slaughterhouse (A29180101) in Ya'an, Sichuan Province, China, during August 28, 2014. Gastric tissue samples of 0.5 to $1 \mathrm{~cm}$ were obtained from the pyloric stomach immediately after slaughtering. The samples were placed in $3 \mathrm{~mL}$ of sterile Brucella broth with $30 \%$ glycerol and transported rapidly to the laboratory.

\section{Culture and collection}

The samples were homogenized in $1 \mathrm{~mL}$ Brucella broth with $30 \%$ glycerol by the use of sterile mortar grinders. A $500 \mu \mathrm{L}$ homogenate of each biopsy specimen was inoculated on selective agar plates (Columbia blood agar supplemented with $7 \%$ fresh defibrinated sheep blood and $3 \%$ vancomycin). Plates were incubated at $37{ }^{\circ} \mathrm{C}$ in a microaerobic atmosphere $\left(5 \% \mathrm{O}_{2}, 10 \% \mathrm{CO}_{2}\right.$, $85 \% \mathrm{~N}_{2}$ ) for 3 to 7 days. Isolates were presumptively identified as $H$. pylori on the basis of colony morphology 
(gray, small, and translucent), Gram staining, rapid urease test and biochemical reactions (oxidase, catalase, and urease positive). The bacterial colonies were collected and prepared in Brucella broth with $10 \%$ fetal calf serum for tests.

\section{Identification \\ DNA extraction}

Five hundred microliters of bacterium solution were centrifuged, and DNA was extracted from the precipitates with the OMEGA Bacterial DNA Kit D3350 according to the manufacturer's protocol. The DNA extracts were eluted in a volume of $200 \mu \mathrm{L}$ and stored in a $20{ }^{\circ} \mathrm{C}$ freezer until PCR was performed.

\section{PCR assays}

PCR amplification of DNA from $H$. pylori strains was performed by the use of species-specific primers (Table 1). All PCRs were performed in $25 \mu \mathrm{L}$ volume and reaction mixtures containing $2.5 \mu \mathrm{L} 10 \times$ buffer $\left(\mathrm{Mg}^{2+}\right), 2.5 \mu \mathrm{L}$ deoxynucleotide triphosphates (dNTPs) at a final concentration of $0.25 \mathrm{mmol} / \mathrm{L}, 1 \mu \mathrm{L}$ of each primer at a final concentration of $0.4 \mu \mathrm{mol} / \mathrm{L}, 0.25 \mu \mathrm{L}$ DNA polymerase (Easy Taq, TransGen Biotech) at a final concentration of $0.05 \mathrm{U} / \mu \mathrm{L}$, and $5 \mu \mathrm{L}$ DNA extracts. PCR amplification of $H$. pylori was performed under these conditions: $3 \mathrm{~min}$ of pre-incubation at $94{ }^{\circ} \mathrm{C}$, followed by 35 cycles of $20 \mathrm{~s}$ at $94{ }^{\circ} \mathrm{C}, 20 \mathrm{~s}$ at $60{ }^{\circ} \mathrm{C}$, and $30 \mathrm{~s}$ at $72{ }^{\circ} \mathrm{C}$. A final extension was performed for $5 \mathrm{~min}$ at $72{ }^{\circ} \mathrm{C}$.

The amplification products were analyzed by the use of gel electrophoresis in $2 \%$ agarose gels and visualized with an ultraviolet light illuminator. Nucleotide sequences were searched by use of the BLAST tool on the National Center for Biotechnology Information site (http://www.ncbi.nlm.nih.gov/ BLAST).

\section{Susceptibility test}

Susceptibility of $H$. pylori strains to TSG and palmatine was determined by use of the agar cup diffusion technique as described [22]. Inoculated plates (Mueller-Hinton agar plates containing $5 \%$ sheep blood) were incubated at $37^{\circ} \mathrm{C}$ in an incubator under microaerophilic conditions for

Table 1 Primer sequences used for $H$. pylori identification

\begin{tabular}{lll}
\hline Target Gene & Oligonucleotides of PCR primer & Products (bp) \\
\hline 16 s rRNA & F: CTGGAGAGACTAAGCCCTCC & 109 \\
& R: ATTACTGACGCTGATTGTGC & \\
ureAB & F: AAAGAGCGTGGTITCATGGCG & 217 \\
& R: GGGTITACCGCCGCCGATTTAA & \\
cagA & F: ATAATGCTAAATAGACAACT & 213 \\
& R: TTAGAATAATCAACAAACATC & \\
vacA & F: ATGCCGCCTIITCACAACC & 204 \\
& R: ACGGCCCATCCACACATTAC & \\
\hline
\end{tabular}

3 to 7 days, after which the diameters of the zones of inhibition ( $\mathrm{mm}$ ) were measured. One percent of dimethyl sulfoxide was included in each plate as a solvent (negative) control; amoxicillin was included as positive controls.

\section{Minimum inhibitory concentration (MIC) and minimum bactericidal concentration (MBC) tests}

Minimum inhibitory concentration (MIC) and minimum bactericidal concentration $(\mathrm{MBC})$ were determined by the use of agar dilution methods according to the Clinical and Laboratory Standards Institute as described [23, 24]. Briefly, the $H$. pylori strains were inoculated on MuellerHinton agar plates containing $5 \%$ sheep blood for 3 to 7 days. The bacterial colonies were collected and prepared in Brucella broth with $10 \%$ fetal calf serum. Inoculates were prepared at a density adjusted to a $1.0 \mathrm{McF}$ arland turbidity $\left(3 \times 10^{8} \mathrm{CFU} / \mathrm{mL}\right)$ standard. Serial dilutions (1:2) of TSG were added to the Mueller-Hinton agar for final concentrations from $200 \mathrm{mg} / \mathrm{mL}$ down to $0.39 \mathrm{mg} / \mathrm{mL}$, and palmatine and clarithromycin (as a positive control) were added to the Mueller-Hinton agar for final concentrations from $200 \mu \mathrm{g} / \mathrm{mL}$ down to $0.39 \mu \mathrm{g} / \mathrm{mL}$. The no-drug containing agar and $1 \%$ dimethyl sulfoxide agar served as negative controls. Agar plates were inoculated with $H$. pylori strains and cultured for 3 days. The MIC was regarded as the lowest concentration that prevented visible growth from a duplicate experiment, and the $\mathrm{MBC}$ was the lowest concentration that completely inhibited bacterial growth.

\section{Bactericidal activities test}

Bactericidal activities were evaluated by the use of timekill curves with $0.5,1$, and $2 \times \mathrm{MIC}$ of drugs, and with blank, clarithromycin, and $1 \%$ dimethyl sulfoxide controls. $H$. pylori SCYA201401 and $H$. pylori SS1 $\left(0.1 \mathrm{~mL}\right.$ at $\left.1 \times 10^{8} \mathrm{CFU} / \mathrm{mL}\right)$ were added to $90-\mathrm{mm}$ plates with the calculated concentrations of drugs or dimethyl sulfoxide and Brucella broth with $10 \%$ fetal calf serum (final volume $10 \mathrm{~mL}$ ), and cultured with gentle shaking at $37{ }^{\circ} \mathrm{C}$ in a microaerobic atmosphere. At 0,4 , $8,12,16,20,24,32,40$ and $48 \mathrm{~h}, 0.1 \mathrm{~mL}$ of liquid was removed, serially diluted, and plated on Columbia blood agar plates ( $n=2$ per group). Colonies were counted and averaged after 3 days of incubation [25].

\section{Model establishment}

A total 108 mice C57BL/6 mice (6-8 week old, male/female $=1: 1$, weight $25 \pm 5 \mathrm{~g}$ ) were purchased from the specific pathogen-free facility at Chengdu Dossy Experimental Animals Co., Ltd. (license No. SCXK, Sichuan, 2013-24). All experimental procedures involving animals were approved by the Sichuan Agricultural University Animal Care and Use Committee (registration No. SCAU2015101801). In accordance with the Guidelines of 
the International Committee on Laboratory Animals, the animals were maintained in environmentally controlled rooms at $20-25{ }^{\circ} \mathrm{C}$ with a relative humidity of $55 \pm 5 \%$ and $12 \mathrm{~h}$ light/dark cycle. Food and water were available ad libitum. Mice were provided with sawdust bedding material and housed under these conditions for one week, then fasted for $12 \mathrm{~h}$ prior to the experiments.

A group of 12 mice, selected randomly as blank control, were inoculated with sterile liquid medium (Brucella broth with $10 \%$ fetal calf serum). A group of 48 mice (the SCYA201401experimental group) was inoculated intragastrically with $0.3 \mathrm{~mL}$ of $H$. pylori SCYA201401 $\left(1 \times 10^{8} \mathrm{CFU} / \mathrm{mL}\right)$ on three alternate days. Another 48 mice (the SS1experimental group) were inoculated intragastrically with $0.3 \mathrm{~mL}$ of $H$. pylori SS1 $\left(1 \times 10^{8} \mathrm{CFU} / \mathrm{mL}\right)$ on three alternate days. Animals were fasted $24 \mathrm{~h}$ before and $2 \mathrm{~h}$ after each inoculation. After 24 days, 8 mice from the SS1 experimental group, 8 mice from the SCYA201401experimental group, and 2 mice from the control group were sacrificed by cervical dislocation without anesthesia prior to the end of the experiment, and used for assessing the by use of a rapid urea test (RUT) and bacterial culture. Only if there was a $100 \%$ infection rate (all 18 mice positive in the RUT and bacterial culture) was the experiment continued.

\section{Group and drug administration}

Mice of two experimental groups were randomly divided into four groups: TSG, palmatine, triple therapy (omeprazole, clarithromycin, and amoxicillin), and model groups. Drugs dosages used in in vivo experiments were equivalent to those that are used clinically. The TSG and palmatine groups were treated intragastrically with $4 \mathrm{~g} / \mathrm{kg}$ and $50 \mathrm{mg} / \mathrm{kg}$ daily for 1 week, respectively. The triple therapy group was treated intragastrically with a suspension of omeprazole $(0.8 \mu \mathrm{g} / \mathrm{kg})$, clarithromycin $(20 \mu \mathrm{g} / \mathrm{kg})$, and amoxicillin $(40 \mu \mathrm{g} / \mathrm{kg})$ daily for 1 week [26]. The SS1 model group, the SCYA201401 model group, and blank control group were given saline solution.

\section{Eradication rate of $H$. pylori}

At the last day of medication, all groups were deprived of feed but allowed free access to water for $24 \mathrm{~h}$ and then sacrificed. Stomachs were collected at the time of sacrifice, opened along the greater curvature, and washed with phosphate-buffered saline at $4{ }^{\circ} \mathrm{C}$. Half of the antral section was isolated for RUT determination at room temperature within $24 \mathrm{~h}$; the change to pink color was regarded as positive. The other half of the antral section and part of the gastric body were used for bacterial culture according to the method described above. Successful eradication of $H$. pylori was defined as negative findings from both RUT and bacterial culture.

\section{Statistical analysis}

Eradication rates were compared among groups with a Fisher's exact test using SPSS 20.0 software (IBM Corp., Armonk, NY, United States). $P<0.05$ was considered statistically significant.

\section{Results}

\section{Bacteria isolated and identified}

Forty-two $H$. pylori strains were isolated from the 170 samples, a culture-positive rate of $24.7 \%$. A total of 128 biopsy samples were negative for $H$. pylori by cultivation. A clinical $H$. pylori strain, containing the gene of cagA and vacA, was named $H$. pylori SCYA201401and was used to following studies.

\section{Bactericidal activity in vitro}

As illustrated in Table 2, the results of antimicrobial susceptibility tests (zone of inhibition, MIC, and MBC) showed that TSG and palmatine had good bactericidal activity in vitro. There was no significant different in susceptibility of $H$. pylori strains SCYA201401 and SS1. The two strains had no visible bacterial colonies after 32-h incubation on the plate containing $6250 \mu \mathrm{g} / \mathrm{mL}$ TSG. The H. pylori SCYA201401 had no visible bacterial colonies after 40 -h incubation with $6.25 \mu \mathrm{g} / \mathrm{mL}$ palmatine, and $H$. pylori SS1 had no growth with $3.12 \mu \mathrm{g} / \mathrm{mL}$ palmatine. Those concentrations defined the MBCs of

Table 2 Results of in vitro bactericidal tests

\begin{tabular}{|c|c|c|c|c|c|c|}
\hline \multirow[t]{2}{*}{ Drugs } & \multicolumn{2}{|c|}{ Diameter of zones of inhibition $(\mathrm{mm}) \pm$ SEM $(100 \mathrm{mg})$} & \multicolumn{2}{|l|}{$\begin{array}{l}\text { MIC } \\
(\mu \mathrm{g} / \mathrm{mL})\end{array}$} & \multicolumn{2}{|l|}{$\begin{array}{l}\mathrm{MBC} \\
(\mu \mathrm{g} / \mathrm{mL})\end{array}$} \\
\hline & $\begin{array}{l}\text { H. pylori } \\
\text { SS1 }\end{array}$ & H. pylori SCYA201401 & $\begin{array}{l}\text { H. pylori } \\
\text { SS1 }\end{array}$ & H. pylori SCYA201401 & $\begin{array}{l}\text { H. pylori } \\
\text { SS1 }\end{array}$ & H. pylori SCYA201401 \\
\hline No-drugs & 0 & 0 & - & - & - & - \\
\hline $1 \%$ DMSO & 0 & 0 & - & - & - & - \\
\hline TSG & $15.00 \pm 0.12$ & $15.48 \pm 0.08$ & 6250 & 6250 & 6250 & 6250 \\
\hline Palmatine & $22.18 \pm 0.00$ & $21.24 \pm 0.02$ & 3.12 & 6.25 & 3.12 & 6.25 \\
\hline Clarithromycin & $16.12 \pm 0.10$ & $23.20 \pm 0.12$ & 32 & 16 & 32 & 16 \\
\hline
\end{tabular}

Notes: TSG, Tinospora sagittata (Oliv.) Gagnep. var. craveniana (S.Y.Hu) Lo (TSG), DMSO dimethyl sulfoxide 
these agents. The results of the antimicrobial susceptibility tests revealed also that the bactericidal activity of palmatine against the $H$. pylori in vitro was significantly more than that of clarithromycin.

Figures 1 and 2 show the time-kill curves of H. pylori SCYA201401 exposed to TSG or palmatine. The average colony count of the blank control and dimethyl sulfoxide control groups increased progressively at every time point. In contrast, the colony counts of the TSG and palmatine groups decreased steadily and did so in a dose-dependent manner. Clarithromyin similarly killed H. pylori SCYA201401.

\section{Bactericidal activity in vivo}

The establishment of the $H$. pylori-infected mice model was evaluated in two ways: identification of $H$. pylori isolated from gastric tissues and the RUT. The bacteria were identified via Gram staining, RUT, and oxidase test and catalase tests. These experiments documented that a H. pylori-infected model was successfully established.

$H$. pylori eradication rates in the mouse model, determined with RUT and bacterial culture, are presented in Table 3. TSG was as effective as triple therapy, but palmatine was modestly less effective than those two treatments.

\section{Discussion}

The major goal of this study was to determine the bactericidal activities of TSG and its major component, palmatine, against $H$. pylori. The rationale underlying the goal is that the current antibiotic treatments of $H$. pylori are becoming less effective and have unwanted side effects and consequences, so effective and safer treatments, perhaps herbal medications, have been needed. In order to accomplish the study's goal we invoked a strategy of isolating $H$. pylori from pigs, inoculating mice with the $H$. pylori, and testing the effectiveness of the traditional Chinese medication, TSG, and its principal active component, palmatine, against the isolated $H$. pylori and standard strain $H$. pylori SS1 in vitro and in vivo. The principal findings of the study are that $H$. pylori isolated from pig could readily colonize mouse stomach and that treatment of $H$. pyloriinfected mice with TSG completely eliminated the $H$. pylori. Thus, the results support the notion that a traditional Chinese medication, TSG, may have therapeutic potential against human $H$. pylori infection.

TSG belongs to Tinosporae (Menispermaceae), which consists of about 34 species, with 8 species found in China. Recent studies have shown that the ethanol extract of Radix Tinosporae significantly inhibited xylene-induced ear edema and acetic acid-induced writhing in mice [20]. TSG has been used in treatment of gastritis and peptic ulcers by the Hmong for more than a thousand years. The chemical constituents of Radix Tinosporae mainly include diterpenoid lactone, protoberberine alkaloids, aporphine alkaloids, and botanic steroids, among which diterpenoid lactones (columbin) and alkaloids (columbamine, jatrorrhizine, palmatine) are considered important bioactive constituents. Phytochemical studies have shown that columbamine, jatrorrhizine, palmatine and menisperine are major diterpenoid lactones and alkaloids compounds in Radix Tinosporae [33]. Although no investigations on antibacterial activity of TSG, columbamine, jatrorrhizine and menisperine against H. pylori have been reported, there are a few reports on palmatine; $16 \mu \mathrm{g} / \mathrm{mL}$ palmatine in vitro or $50 \mathrm{mg} / \mathrm{kg}$ in vivo killed $H$. pylori [34, 35].

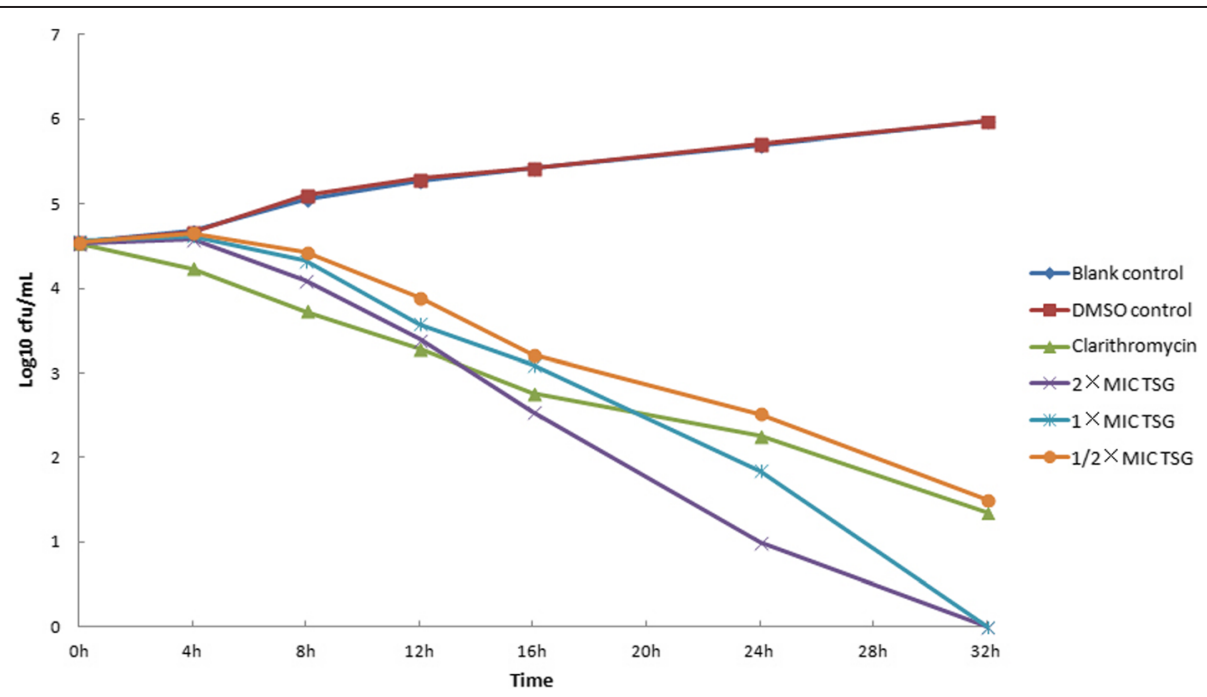

Fig. 1 Time-kill curves of Tinospora sagittata (Oliv.) Gagnep. var. craveniana (S.Y.Hu) Lo against H. pylori SCYA201401 at different concentrations. Notes: MIC: minimum inhibitory concentration; TSG: Tinospora sagittata (Oliv.) Gagnep. var. craveniana (S.Y.Hu) LO 


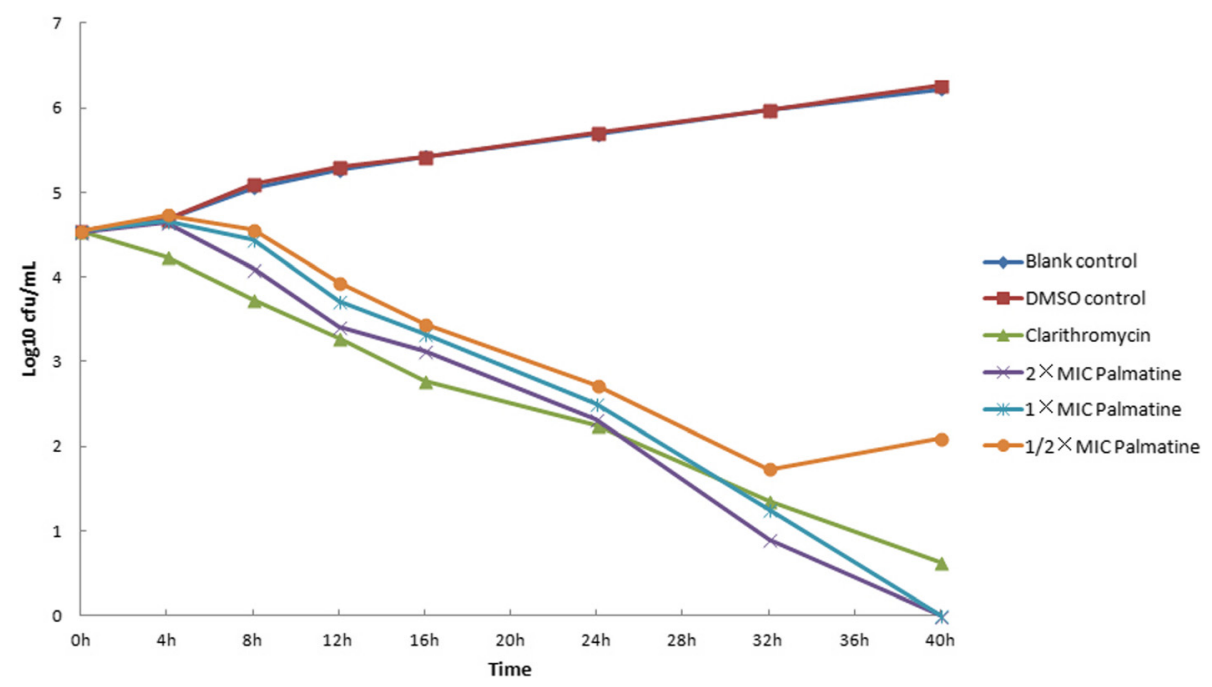

Fig. 2 Time-kill curves of palmatine against H. pylori SCYA201401 at different concentrations. Note: MIC: minimum inhibitory concentration

In our study, the MIC of TSG, $6.25 \mathrm{mg} / \mathrm{mL}$, was sufficient to completely eliminate $H$. pylori. Although this MIC is lower than that in another study $(16 \mu \mathrm{g} /$ $\mathrm{mL}$ ) [35], it took longer than TSG to completely eliminate the $H$. pylori strains we used. Our in vivo experiments demonstrated the potential of TSG for eradication of $H$. pylori, with efficacy equivalent to that of triple therapy. The observation that palmatine was less effective than TSG, implies that palmatine is not the only component of TSG with bactericidal effect against $H$. pylori. Like other herbs, TSG is a complex compound, and some of it effective components likely are yet unknown. Hence, further research on TSG might prove useful in identifying components that could have greater anti-H. pylori effect than has palmatine. Nevertheless, this study confirms the in vitro and in vivo anti- $H$. pylori effects of TSG and its main component palmatine, and provide impetus for future research with these agents.

The findings of our initial experiments with abattoir pigs have important implications. We found a substantial isolation rate (about $25 \%$ ) in abattoir pigs. Others [27] have reported that in 60 farms in England, over $79 \%$ of porcine stomachs had either an oesophago-gastric ulcer or visible pre-ulcerative changes. Although it was not proven that $H$. pylori caused the abnormalities, it may have, or the abnormalities may have been caused by a related bacterium, such as Helicobacter heilmanni. The ease of transmission of porcine $H$. pylori to mice in our study indicates the possibility of zoonotic transmission of H. pylori. Accordingly, colonization of domestic animals has to be considered a possible cause of the high prevalence of $H$. pylori infections in man.

The current medicinal treatment of $H$. pylori is generally based on triple therapy regimen, inhibition of gastric acid secretion by histamine $\mathrm{H}_{2}$-antagonists, proton pump inhibitors, as well as on mucosal protective therapy provided by sucralfate and bismuth $[28,29]$. Since antibiotic-resistant $H$. pylori strains triggered a global pandemic and brought various harmful adverse effects, the search for safe and effective non-antibiotic agents is urgently required [30,31]. In recent years, active researches have rekindled interest in natural drugs possessing these activities, which are widely appreciated by the population especially in oriental countries [32].

Since improved medical therapy for human H. pylori infection is clearly needed, the results of this study are encouraging. Although their relevance to the management

Table 3 Results of rapid urease test and bacterial culture in the mouse model $(n=10)$

\begin{tabular}{|c|c|c|c|c|c|c|c|c|c|}
\hline \multirow[t]{2}{*}{ Tests } & \multirow{2}{*}{$\begin{array}{l}\text { Blank } \\
\text { control }\end{array}$} & \multicolumn{4}{|c|}{ SCYA201401 experimental group } & \multicolumn{4}{|c|}{ SS1 experimental group } \\
\hline & & Model & Triple therapy & TSG & Palmatine & Model & Triple therapy & TSG & Palmatine \\
\hline rapid urease test (n) & 10 & 0 & 7 & 9 & 5 & 0 & 7 & 9 & 6 \\
\hline Bacterial culture (n) & 10 & 0 & 7 & 8 & 5 & 0 & 7 & 8 & 6 \\
\hline Eradication ratio & - & $0 / 10$ & $7 / 10$ & $8 / 10$ & $5 / 10^{*}$ & $0 / 10$ & $7 / 10$ & $8 / 10$ & $6 / 10$ \\
\hline
\end{tabular}

${ }^{*} P<0.05$ vs. TSG group 
of human $H$. pylori infection is unknown, they do indicate that non-antibiotic-based treatment options, such as herbal medication, deserve consideration.

\section{Conclusions}

In experiments with an $H$. pylori strain isolated from pigs and standard strain $H$. pylori SS1, the Chinese herbal medicine TSG and is major active component, palmatine, exhibited bactericidal effect in vitro and in a murine model. The effect was of similar magnitude to that of clarithromycin or triple therapy. In view of the increasing antibiotic resistance of $H$. pylori and the side effects associated with antibiotic-based therapy, the possibility that herbal medications could provide effective and safe therapy of $H$. pylori infection deserves investigation.

\section{Acknowledgments}

This work was supported in part by a grant (2013NZ0019) from the Science and Technology Department of Sichuan Province, China. We thank the College of Veterinary Medicine, Sichuan Agricultural University, Cheng du 611130, China, for kindly providing facilities.

\section{Funding}

This study was supported in part by a grant (2013NZ0019) from the Science and Technology Department of Sichuan Province, China.

\section{Availability of data and materials}

The datasets supporting the conclusions of this article are included within the article.

\section{Authors' contributions}

QR carried out most of the experiments and drafted the manuscript. YL, GY and LZ critically revised the experiment design and manuscript. MX, QD and $Y L$ helped with the experiment. All authors read and approved the final manuscript.

\section{Competing interests}

The authors declare that they have no competing interests.

\section{Consent for publication}

Not applicable.

\section{Ethics approval and consent to participate}

All experimental procedures involving animals were approved by Sichuan Agricultural University Animal Care and Use Committee (registration No. SCAU2015101801). In accordance with the Guidelines of the International Committee on Laboratory Animals, they were maintained in environmentally controlled rooms at $20-25^{\circ} \mathrm{C}$ with a relative humidity of $55 \pm 5 \%$ and $12 \mathrm{~h}$ light/dark cycle. Food and water could be available ad libitum. Animals were provided with sawdust bedding material and were housed under these conditions for one week prior to the experiments.

Received: 16 March 2016 Accepted: 20 August 2016

Published online: 30 August 2016

\section{References}

1. Parsonnet J, Friedman GD, Vandersteen DP, et al. Helicobacter pylori infection and the risk of gastric carcinoma. N Engl J Med. 1991;325(16):1127-31.

2. Graham DY, Lew GM, Klein PD, et al. Effect of treatment of Helicobacter pylori infection on the long-term recurrence of gastric or duodenal ulcer: a randomized, controlled study. Ann Intern Med. 1992;116(9):705-8.

3. Kuipers EJ, Pena AS, Festen HPM, et al. Long-term sequelae of Helicobacter pylori gastritis. Lancet. 1995;345(8964):1525-8.

4. Parsonnet J, Hansen $\mathrm{S}$, Rodriguez $\mathrm{L}$, et al. Helicobacter pylori infection and gastric lymphoma. N Engl J Med. 1994;330(18):1267-71.
5. Nervi G, Liatopoulou S, Cavallaro LG, et al. Does Helicobacter pylori infection eradication modify peptic ulcer prevalence? A 10 years' endoscopical survey. World J Gastroenterol. 2006;12(15):2398-401.

6. Fischbach W, Goebeler-Kolve ME, Dragosics B, et al. Long term outcome of patients with gastric marginal zone B cell lymphoma of mucosa associated lymphoid tissue (MALT) following exclusive Helicobacter pylori eradication therapy: experience from a large prospective series. Gut. 2004;53(1):34-7.

7. Konturek PC, Konturek SJ, Brzozowski T. Helicobacter pylori infection in gastric cancerogenesis. J Physiol Pharmacol. 2009;60(3):3-21.

8. Husson MO, Vincent P, Grabiaud MH, et al. Anti-Helicobacter pylori lgG levels in abattoir workers. Gastroenterol Clin Biol. 1990;15(10):723-6.

9. Mohamed A A, El-Gohari A H: Epidemiological aspects of Helicobacter pylori infections as an emergence zoonotic disease: Animal reservoirs and public health implications (A review article). 7th Int Sci Conf, MANSOURA 2012:17-25.

10. Dore MP, Sepulveda AR, El-Zimaity H, et al. Isolation of Helicobacter pylori from sheep-implications for transmission to humans. Am J Gastroenterol. 2001;96(5):1396-401

11. Kolodzieyski L, Kim B, Park H, Yoon HS, Lim CW. Prevalence of gastrospirillum-like organisms in pigs, cattle, and dogs: a comparison of diagnostic methods between species. Vet Med. 2008;53:193-202.

12. Quaglia NC, Dambrosio A, Normanno G, et al. High occurrence of Helicobacter pylori in raw goat, sheep and cow milk inferred by glmM gene: a risk of food-borne infection? Int J Food Microbiol. 2008;124(1):43-7.

13. Lawal TO, Olorunnipa TA, Adeniyi BA. Susceptibility testing and bactericidal activities of Theobroma cacao Linn. (cocoa) on Helicobacter pylori in an in vitro study. J Herb Med. 2014;4(4):201-7.

14. Liu P, Kong M, Yuan S, et al. History and experience: a survey of traditional chinese medicine treatment for Alzheimer's disease. Evid Based Complement Alternat Med. 2014;2014:642128.

15. Xu LW, Jia M, Salchow R, et al. Efficacy and side effects of chinese herbal medicine for menopausal symptoms: a critical review. Evid Based Complement Alternat Med. 2012;2012(1):568106.

16. Zhang S, Mo F, Luo Z, et al. Flavonoid Glycosides of Polygonum capitatum Protect against Inflammation Associated with Helicobacter pylori Infection. Plos One. 2015;10(5):e0126584.

17. Jagetia GC, Nayak V, Vidyasagar MS. Evaluation of the antineoplastic activity of guduchi (Tinospora cordifolia) in cultured HeLa cells. Cancer Lett. 1998; 127:71-82.

18. Khan MA, Gray Al, Waterman PG. Tinosporaside, an 18-norclerodane glucoside from Tinospora cordifolia. Phytochemistry. 1989;28(1):273-5.

19. Wei L, Kazuo K, Lijuan L, et al. New lignan glucosides from the stems of Tinospora sinensis. Chem Pharm Bull. 2004;52(5):638-40.

20. Qin NB, Wang AL, Li DH, et al. Cytotoxic clerodane furanoditerpenoids from the root of Tinospora sagittata. Phytochem Lett. 2015;12:173-6.

21. Liu X, Hu Z, Shi Q, et al. Anti-inflammatory and anti-nociceptive activities of compounds from Tinospora sagittata (Oliv.) Gagnep. Arch Pharm Res. 2010;33(7):981-7.

22. Lawal TO, Igbokwe CO, Adeniyi BA. Antimicrobial activities and the Bactericidal Kinetics of Allium ascalonicum Linn. (Whole plant) against standard and clinical strains of Helicobacter pylori: Support for Ethnomedical Use. J Nat Sci Res. 2014;4(8):48-56.

23. Clinical and Laboratory Standards Institute. Performance Standards for Antimicrobial Susceptibility Testing: Twenty-first Informational Supplement M100-S21. Wayne: CLSI; 2011.

24. Silva LP, de Angelis CD, Bonamin F, et al. Terminalia catappa L.: A medicinal plant from the Caribbean pharmacopeia with anti-Helicobacter pylori and antiulcer action in experimental rodent models. J Ethnopharmacol. 2015;159:285-95.

25. Hui Y, Yu L, Ning L, et al. Anti-Helicobacter pylori activities of Chenopodium ambrosioides L. in vitro and in vivo. World J Gastroenterol. 2015;21(14):4178-83.

26. Park CS, Lee SM, Park CH, et al. Pretreatment antimicrobial susceptibilityguided vs. clarithromycin-based triple therapy for Helicobacter pylori eradication in a region with high rates of multiple drug resistance. Am J Gastroenterol. 2014;109(10):1595-602.

27. Swaby H, Gregory NG. A note on the frequency of gastric ulcers detected during post-mortem examination at a pig abattoir. Meat Sci. 2012;90(1):269-71.

28. Bighetti AE, Antonio MA, Kohn LK, et al. Antiulcerogenic activity of a crude hydroalcoholic extract and coumarin isolated from Mikania laevigata Schultz Bip. Phytomedicine. 2005;12(1):72-7. 
29. Miwa H, Sakaki N, Sugano K, et al. Recurrent peptic ulcers in patients following successful Helicobacter pylori eradication: a multicenter study of 4940 patients. Helicobacter. 2004;9(1):9-16.

30. Liu J, He L, Haesebrouck F, et al. Prevalence of Coinfection with Gastric Non-Helicobacter pylori Helicobacter (NHPH) Species in Helicobacter pyloriinfected Patients Suffering from Gastric Disease in Beijing, China[J]. Helicobacter, 2015;20(4):284-290.

31. Kusters JG, van Vliet AHM, Kuipers EJ. Pathogenesis of Helicobacter pylori infection. Clin Microbiol Rev. 2006;19(3):449-90.

32. Xie $\mathrm{JH}$, Chen $\mathrm{YL}, \mathrm{Wu} \mathrm{QH}$, et al. Gastroprotective and anti-Helicobacter pylori potential of herbal formula HZJW: safety and efficacy assessment. BMC Complement Altern Med. 2013;13(1):119.

33. Moody JO, Robert VA, Connolly JD, et al. Anti-inflammatory activities of the methanol extracts and an isolated furanoditerpene constituent of Sphenocentrum jollyanum Pierre (Menispermaceae). J Ethnopharmacol. 2006;104(1):87-91.

34. Boda M, Tan PV, Nyasse B. Rapid in vivo screening method for the evaluation of new anti helicobacter medicinal preparations. Afr J Tradit Complement Altern Med. 2006;3(4):102-14.

35. Jung J, Choi JS, Jeong CS. Inhibitory activities of palmatine from coptis chinensis against helicobactor pylori and gastric damage. Toxicol Res. 2014;30(1):45

\section{Submit your next manuscript to BioMed Central} and we will help you at every step:

- We accept pre-submission inquiries

- Our selector tool helps you to find the most relevant journal

- We provide round the clock customer support

- Convenient online submission

- Thorough peer review

- Inclusion in PubMed and all major indexing services

- Maximum visibility for your research

Submit your manuscript at www.biomedcentral.com/submit 